The development of national ingroup bias: English children's attributions of characteristics to English, American and German people

\author{
Martyn Barrett, Hannah Wilson \& Evanthia Lyons \\ Department of Psychology \\ University of Surrey
}

Address for correspondence: Martyn Barrett, Department of Psychology, University of Surrey, Guildford, Surrey GU2 7XH, UK

Tel: $++44-(0) 1483-686862$

Fax: ++44-(0)1483-879553

Email: m.barrett@surrey.ac.uk

Acknowledgements: We would like to thank all the staff and pupils of Fleet Infant and Velmead County Junior Schools, Fleet, Hampshire, especially Miss L. Harris and Mrs L. Smith, for their help and co-operation in conducting this research. We are also grateful to Lynne Millward, Rupert Brown and Mark Bennett for comments on an earlier version of this paper. Some of the findings from the study reported in this paper were first presented in a poster entitled 'Self-categorization theory and the development of national identity in English children' at the Biennial Meeting of the Society for Research in Child Development, Albuquerque, New Mexico, USA, April $15^{\text {th }}-18^{\text {th }}$, 1999. This research was supported by ESRC Research Studentship No. R00429434366 awarded to the second author. 


\title{
The development of national ingroup bias: English children's attributions of characteristics to English, American and German people
}

\begin{abstract}
This study investigated the development of national ingroup bias in 5-11-year-old children. Three hundred and seven English children were asked to attribute characteristics to their own national group either on its own or in conjunction with attributing characteristics to one of two national outgroups, either Americans or Germans. The importance which the children ascribed to their own national identity in relationship to their other social identities was also assessed. It was found that, with increasing age, there was an increase in the number of negative characteristics which were attributed to the national ingroup, and an increase in the number of positive characteristics which were attributed to the two outgroups, the net result being an overall reduction in ingroup bias across this age range. However, ingroup favouritism was still exhibited at all ages. Greater importance was attributed to national identity with increasing age. However, the characteristics which were attributed to the English ingroup did not vary as a function of the comparative outgroup which was present while the attributions were being made. The presence of a comparative outgroup also did not affect the importance which was ascribed to the national identity. These findings suggest that children are relatively insensitive to the prevailing comparative context when making judgements about national groups.
\end{abstract}


The development of national ingroup bias: English children's attributions of characteristics to English, American and German people

Introduction

This study investigated the development of national ingroup bias in children, focussing in particular upon English children's attribution of characteristics to their own national group and to two national outgroups, namely Americans and Germans. Previous studies which have investigated children's representations of national groups have shown that, up until about 5 years of age, children often have very little knowledge of nations and national groups, and may even be unable to state the name of their own country (Piaget \& Weil, 1951). However, from about 5 years of age onwards, children can provide the name of their own country, and begin to categorise themselves as members of their own national group (Barrett, 1996; Wilson, 1998). During middle childhood, knowledge of the people who belong to different national groups expands considerably (Barrett \& Short, 1992; Jahoda, 1962; Lambert \& Klineberg, 1967; Piaget \& Weil, 1951) and, by 10 or 11 years of age, children are able to describe many of the characteristics which are exhibited by members of their own and other national groups, including their typical physical features and appearance, clothing, language, behavioural habits, psychological traits, and political and religious beliefs (Lambert \& Klineberg, 1967; Piaget and Weil, 1951).

This acquisition of knowledge about national groups during middle childhood is usually accompanied by the acquisition of a systematic preference for members of the national ingroup over members of national outgroups, sometimes from as early as 5 or 6 years of age (Barrett, in press; Barrett, Lyons \& del Valle, in press; Bennett et al., in press; Bennett, Lyons, Sani \& Barrett, 1998; Lambert \& Klineberg, 1967; Tajfel, Jahoda, Nemeth, Campbell \& Johnson, 1970; Wilson, 1998; although cf. Rutland, 1999, who only found ingroup favouritism appearing from 10 years of age onwards). However, although children do usually acquire an ingroup preference during middle childhood, it is clear from many studies that children may still sometimes feel very positively about some national outgroups (Barrett \& Short, 1992; Johnson, Middleton \& Tajfel, 1970; Lambert \& Klineberg, 1967; Middleton, Tajfel \& Johnson, 1970). The relative order of preference for other national groups, once it is established (perhaps by 6 years of age), seems to remain fairly stable and consistent across the remaining childhood years (Barrett \& Short, 1992; Jaspers, van de Geer, Tajfel \& Johnson, 1972; Johnson et al., 1970). However, the overall degree of liking of all national outgroups tends to increase between 5 and 11 years of age (Barrett \& Short, 1992; Lambert \& Klineberg, 1967). After 11 years of age, this general increase in positive regard for other national groups usually levels out (Lambert \& Klineberg, 1967).

It is noteworthy that this increase in positive regard for national outgroups takes place at the same time as the reduction in ethnic ingroup bias in white majority group children; ethnic ingroup bias in such children has been found to peak at about 6 years of age, and to show a steady decline between 6 and 12 years of age (Aboud, 1988; Aboud \& Amato, 2001; Bigler \& Liben, 1993; Davey 1983; Katz \& Zalk, 1978; Vaughan, 1964; Williams \& Morland, 1976). Investigating this trend using an adjective attribution task, Doyle, Beaudet and Aboud (1988) and Doyle and Aboud (1995) found that, at the age of 5 or 6, children attribute mainly positive adjectives to members of their own ethnic group, and mainly negative adjectives to members of other ethnic groups. Between 6 and 12 years of age, this polarisation in the attribution of adjectives decreases, as the child gradually comes to attribute both positive and negative attributes to both the ethnic ingroup and outgroups. On the basis of 
these findings, Doyle et al. (1988) argue that the reduction of ethnic ingroup bias during middle childhood is due to the increasing recognition across this age range that all ethnic groups contain all kinds of people exhibiting both positive and negative characteristics. Doyle and Aboud (1995) further argue that this shift in the conceptualisation of ethnic groups is itself based upon underlying socio-cognitive changes in the way that large-scale social groups are conceptualised, involving perceptions of greater similarity between social groups, greater variability within social groups, and the legitimacy of outgroup members' preferences.

If Doyle and Aboud (1995) are correct in their reasoning, namely that the reduction in ethnic ingroup bias during middle childhood is due to an underlying socio-cognitive change in children's understanding of large-scale social groups, then it should be possible to observe a comparable shift in the attributions which children make to national groups across the middle childhood years. One of the goals of the present study was to ascertain whether such a shift does indeed occur in the nationality domain. In this study, 5-11-year-old English children were asked to attribute characteristics both to their national ingroup (English people) and to two national outgroups (Americans and Germans). It was anticipated that, across this age range, there would be an increase in the negativity of attributions to the national ingroup, and an increase in the positivity of attributions to the two national outgroups, such that by 11 years of age, the children would be attributing a mixture of both positive and negative characteristics to all three national groups, i.e. that there would be a similar pattern of development to that shown in the ethnic domain.

The present study used a different method to assess children's attributions of characteristics to national groups from the ones which have been used in many previous studies. As both Aboud (1988) and Cameron, Alvarez, Ruble and Fuligni (2001) have pointed out, early studies which were conducted into children's ethnic ingroup bias (e.g. Asher \& Allen, 1969; Clark \& Clark, 1947/1958) relied upon giving children a set of dolls or puppets representing different social groups and asking the child to choose, for example, which one 'looks bad'/ 'you would like to play with'/ 'is a nice doll', etc., a forced-choice measure which confounds acceptance of one target with rejection of the other target. In order to overcome this problem, Aboud's own studies (e.g. Doyle \& Aboud, 1995) instead utilise the Multiresponse Racial Attitude (MRA) measure in which children have to attribute characteristics (the names of which are written on cards) to boxes, each box representing a particular target group (e.g. White, Black, etc.). The child is explicitly instructed to assign characteristics to a 'both' box if he or she believes that both targets possess that characteristic. However, as Cameron et al. point out, this method still does not allow children the opportunity to say that no group possesses that characteristic, thus still biasing the measurement of the child's evaluations of both ingroups and outgroups. The present study avoided this problem by explicitly instructing the children to discard any characteristics which they thought did not apply to any of the target groups.

In the domain of nationality, there are many different outgroups against which the national ingroup can be compared. Americans and Germans were chosen for use in the present study because previous research has shown that, for 5-11-year-old English children, Americans are a highly salient national outgroup, who are typically perceived to be 'friendly' and 'good', and are usually liked more than any other national outgroup (Wilson, 1998; Wilson, Barrett \& Lyons, 1995). By contrast, Germans have been found to be a highly salient but disliked national outgroup for 5-11-year-old English children, who tend to view German people as 'aggressive' and 'hardworking', and typically exhibit more negative affect towards 
Germans than towards any other national outgroup (Barrett, Day \& Morris, 1990; Barrett et al., in press; Barrett \& Short, 1992; Johnson, 1966, 1973; Johnson et al. 1970; Wilson et al., 1995). English children usually begin to exhibit their affective responses to Americans and Germans by the age of 5, with more detailed stereotype content (e.g. the attributions of friendliness, aggressiveness, etc.) being exhibited by 7 or 8 years of age (Barrett \& Short, 1992; Wilson et al., 1995). Thus, Americans and Germans were used in this study because:

(a) both groups are salient national outgroups for English children; (b) stereotype content for these two outgroups is known to be developing during the age-range under investigation; (c) Americans tend to be the most liked and Germans the most disliked national outgroup for English children and these two groups therefore provide a robust test of the developmental prediction concerning the attribution of negative and positive characteristics to national outgroups.

A second issue which this study was designed to investigate was whether children's attributions to the national ingroup vary according to the specific comparative context which prevails at the time that these attributions are made. In the study of adults' national stereotypes, it has been found that the comparative context within which stereotypes are elicited is an important factor in determining the contents of both ingroup and outgroup stereotypes (Diab, 1963a, 1963b; Haslam, Turner, Oakes, McGarty \& Hayes, 1992; Haslam, Oakes, Turner \& McGarty, 1995; Hopkins \& Murdoch, 1999; Hopkins, Regan \& Abell, 1997; Oakes, Haslam \& Turner, 1994; Spears \& Manstead, 1989). For example, Hopkins et al. (1997) found that the contents of the national ingroup stereotype varies according to the particular comparison outgroup in relationship to which the ingroup is being judged. They asked adult Scottish participants to attribute adjectives to their own national group in one of three conditions: after evaluating the English, after evaluating the Greeks, and in isolation. Because of the common prevailing stereotypes held by the Scots that the English are arrogant and cold, and the Greeks are comparatively lazy but considerably warmer, it was predicted that the Scots would evaluate themselves as friendly and warm after having evaluated the English, but as hardworking and not as warm after evaluating the Greeks. It was found that the Scottish self-stereotype did indeed vary as a function of comparative context in the predicted manner. Stereotype variability as a function of comparative context has also been found to occur with 5- and 7-year-old children's gender stereotypes. Sani and Bennett (2001; Sani, Bennett, Mullally \& MacPherson, in press) found that 5- and 7-year old boys make different attributions to boys depending upon whether the comparative context comprised girls or men; thus, they are more likely to attribute 'brave', 'big' and 'strong' to boys having previously considered girls, but are more likely to attribute 'talkative' to boys having previously considered men. Similar effects were found to occur in girls' attributions to girls (depending upon whether they were considered in a comparative context comprising boys or women).

The present study was therefore designed to ascertain whether children's national stereotypes also display variability as a function of the comparative frame of reference. In this study, the children were asked to attribute characteristics to English people under three different conditions: either when judging English people on their own, when judging them in conjunction with Americans, or when judging them in conjunction with Germans. Because previous studies have revealed that Americans and Germans are salient national outgroups for English children, and because English children typically attribute different characteristics to these two outgroups (i.e. 'friendly' and 'good' to Americans, and 'aggressive' and 'hardworking' to Germans), the aim was to ascertain whether the children would attribute 
different characteristics to English people depending upon the comparative context. More specifically, the data were examined in order to find out whether the children were less likely to attribute the characteristics of 'friendly' and 'good' to English people when evaluating them in comparison to Americans, and less likely to attribute the characteristics of 'aggressive' and 'hardworking' to English people when evaluating them in comparison to Germans. In addition, the analyses examined whether there were changes in the attribution of the polar opposite terms, namely 'unfriendly', 'bad', 'peaceful' and 'lazy'. Because of the robustness of the effects of comparative context upon stereotype content in adults, and the occurrence of similar effects in children's gender stereotypes, it was anticipated that such context-dependent shifts in national stereotype content would occur at least from the age of 8 years onwards, when the more detailed representational content of the American and German stereotypes has normally been acquired by English children.

A third issue which was investigated in this study concerned the importance which children attribute to their national identity. In a cross-national study which examined the development of national identity in 6-15-year-old children growing up in Britain, Spain and Italy, Barrett, Lyons, Bennett, Vila, Giménez de la Peña, Arcuri and de Rosa (1997) asked the children, in a non-comparative context, to rate the importance of their national identity in relationship to the importance of their gender, age, city, regional and European identities. It was found that between 6 and 12 years of age, national identity gradually became more important to these children; however, even at 12 years of age, the children's gender and age identities were still more important to them than their national identity. A similar finding was obtained by Wilson and Barrett (1996) with 5-11-year-old English children. This finding is not surprising, given that national identity probably has a lower utility than either gender or age in children's immediate everyday social environment, as it usually does not provide a basis for social differentiation within this context.

That said, it is possible that, when national identity is elicited in an intergroup comparative context (for example, in the context of an international sporting event, or when the child is on holiday in another country), it may be more important to the child than either gender or age. Indeed, research with adults has revealed that the importance or the salience of an identity is usually higher within intergroup comparative situations than within situations in which only the ingroup is present (see Oakes et al., 1994). Oakes et al. argue that this effect occurs because the latter kind of situation encourages intra-group comparisons, increasing the perceived variability of the ingroup, and enhancing the salience of lower-level personal (or sub-group) categories between which the differences are accentuated. By contrast, in intergroup comparative contexts which contain both the ingroup and a salient outgroup, intragroup differentiations within the ingroup become less salient, the perceived variability of the ingroup decreases, and the salience of the ingroup category increases.

In order to examine whether such effects occur in children, a similar task to that used by Barrett et al. (1997) was administered in the present study immediately after the child had completed the adjective attribution task. This task assessed the relative importance of the national identity to the child. The aim was to ascertain whether the national identity would be rated as being less important than other identities in the condition in which only the English national group was administered on its own; and whether in the two comparative conditions in which the national ingroup was presented in conjunction with a salient outgroup (American or German), the importance of the national identity, relative to other identities, would be enhanced. Independently, and in line with the previous findings of Barrett et al. (1997) and 
Wilson and Barrett (1996), it was expected that the importance of national identity would increase as a function of age.

To summarise: this study involved asking English children, aged between 5 and 11 years old, to attribute characteristics to their own national ingroup (English) either alone in a non-comparative context, or in a comparative context in which they were also asked to attribute characteristics to either a liked outgroup (American) or a disliked outgroup (German). The children were then asked to complete a second task in which the importance of their national identity in relationship to their other social identities was assessed. There were four predictions:

(1) That there would be an increase in the negativity of attributions to the English ingroup, and an increase in the positivity of attributions to the two outgroups, across this age range, such that by 11 years of age, the children would be attributing a mixture of both positive and negative characteristics both to the ingroup and to the two outgroups.

(2) That the children would assign different characteristics to English people when they judged them in relationship to American vs. German people vs. alone. In particular, it was hypothesised that they would be less likely to describe English people as being 'friendly' or 'good' when evaluating them in comparison to Americans, and would be less likely to describe English people as being 'aggressive' (or more likely to evaluate them as being 'peaceful') and 'hardworking' when evaluating them in comparison to Germans.

(3) That the importance ascribed to the national identity in relationship to the children's other social identities would increase as a function of age.

(4) That the national identity would be rated by the children as being less important in the non-comparative condition in which only the English national ingroup was presented than in the two comparative conditions in which the national ingroup was presented in conjunction with a salient outgroup (either American or German).

\section{Method}

\section{Participants}

Three hundred and seven English children aged between 5 years 7 months and 11 years 9 months participated in the study. All of the children lived in the town of Fleet in Hampshire, and all were of British nationality. There were 151 boys and 156 girls. The children were divided into three age groups according to their school years: school Years 1 and $2(\mathrm{~N}=116)$, school Years 3 and $4(\mathrm{~N}=95)$, and school Years 5 and $6(\mathrm{~N}=96)$. These three age groups are henceforward called the Young, Middle, and Old age groups.

Within each age group, the children were further subdivided randomly into three experimental conditions: a non-comparative condition, attributing characteristics to English people alone; an American comparative condition, attributing characteristics to English and American people together; and a German comparative condition, attributing characteristics to English and German people together. The mean age, age range and number of children within each condition are shown in Table 1.

\section{* INSERT TABLE 1 ABOUT HERE *}




\section{Procedure and Materials}

Each child was interviewed separately in a quiet room made available in their school. After establishing rapport with the child, it was explained that the interviewer was interested in finding out what the child thought about certain things. Reassurance was given that this was not a test, that there were no right or wrong answers, and that no one other than the interviewer would know what they had said. The tasks which the children were given required the selection and organising of words which were printed on cards. The interviewer was alert to possible weaknesses in the children's reading skills, and assistance in reading the cards was provided wherever necessary. The children in all of the conditions completed two tasks: an attribution task immediately followed by a relative subjective importance task.

\section{The attribution task}

Five boxes measuring $15 \times 15 \times 15 \mathrm{cms}$. were used in the attribution task. Written on each box was either 'English', 'American', 'German', 'both' or 'neither'. Each box had a posting slot across the front measuring the full width of the box. The materials also included 16 cards measuring $8 \times 3 \mathrm{cms}$. On each of the cards was written one of the following words: 'clean', 'dirty', 'happy', 'sad', 'peaceful', 'aggressive', 'clever', 'stupid', 'hardworking', 'lazy', 'friendly', 'unfriendly', 'good', 'bad', 'nice', and 'not nice'.

These pairs of bipolar adjectives were chosen for a number of reasons. Firstly, previous studies have found that these are all terms which children themselves produce spontaneously when asked to describe national groups (Barrett et al., 1990; Lambert \& Klineberg, 1967) and which children themselves comprehend and apply differentially and selectively to different national groups (Barrett \& Short, 1992). Secondly, the 'friendly'/'unfriendly', 'good'/'bad', 'peaceful'/'aggressive' and 'hardworking'/'lazy' pairs of adjectives were included because they were required for testing the specific prediction concerning changes in the children's attribution of these particular characteristics to English people when compared to Americans vs. Germans. Thirdly, similar evaluative adjectives (e.g. 'nice', 'bad') and descriptive adjectives (e.g. 'clean', 'happy') were used in those studies into children's ethnic ingroup bias that yielded the developmental findings the generality of which were to be tested in this study (for example, Doyle et al.'s 1988 study used, amongst other terms, 'clean', 'dirty', 'happy', 'sad', 'smart', 'stupid', 'friendly', 'unfriendly', 'good', 'bad' and 'nice', words taken from the Preschool Racial Attitude Measure II: Williams, Best, Boswell, Mattson \& Graves, 1975). Thus, these particular terms were chosen for use in this study because they are precisely the sorts of terms which children themselves use spontaneously in order to characterise both national and ethnic groups, the dimensions which they capture are of known relevance to children's descriptions of national and ethnic groups, and some of the terms that were included were required for testing the specific predictions underlying the study.

In the American comparative condition, the child was presented with the four boxes that were labelled 'English', 'American', 'both' and 'neither'. In the German comparative condition, the child was presented with the four boxes labelled 'English', 'German', 'both' and 'neither'. In these two comparative conditions, the position of the first two boxes was counterbalanced across successive children. The positions of the 'both' and 'neither' boxes were held constant, and they were presented in that order to the right of the other two boxes. In the non-comparative condition, the child was presented with the 'English' box on its own. 
The 16 cards with the adjectives on them were then placed in a randomly ordered pile in front of the child. In the two comparative conditions, the child was instructed to place each card into the box representing the national group which they thought that word described. If the word could be used to describe both groups, the child was told to place it into the 'both' box. If the word was thought not to be applicable to either group, they were told to place it into the 'neither' box. In the non-comparative condition, the child was simply instructed to place all the words into the English box which they thought could be used to describe English people. If the child thought that any of the words were not applicable, they were told to put them to one side. Thus, the child was not forced to use all of the cards, and was free to discard any cards which he or she felt were not appropriate in describing either the ingroup or the outgroups. This was in order to ensure that the results from each individual child would only be based upon adjectives that were actually relevant to the child's own representations of English, American and German people; adjectives which were irrelevant to the child's own judgement could be discarded by the child. Hence, the task avoided the methodological problems noted by Cameron et al. (2001), and independently assessed the child's own positive and negative attributions to the ingroup and outgroups.

The verbatim instructions which were used in the task were as follows. In the two comparative conditions: "Look, here are lots of different words which can be used to describe people. I want you to think about English and \{German/American\} people. Can you go through these words one at a time, and put each word into one of these four boxes. If you think the word can only be used to describe English people, then put it in the English box. However, if you think the word can only be used to describe \{German/American\} people, then put it in the \{German/American\} box. But if you think the word can be used to describe both English and \{German/American\} people, then put it in the 'both' box. And if you think the word cannot be used to describe either English or \{German/American\} people, then put it in the box which says 'neither'. Is that clear?" In the non-comparative condition: "Look, here are lots of different words which can be used to describe people. I want you to think about English people. Can go through these words one at a time. If you think the word can be used to describe English people, then put it in the English box. However, if you think the word cannot be used to describe English people, then put it down over here. Is that clear?" In a small handful of cases, which typically involved the youngest children, if the child seemed confused by a particular word on a card, a simple paraphrase was given to the child (e.g. 'aggressive' was glossed as 'likes to fight other people', and 'peaceful' as 'does not like fighting other people').

The relative subjective importance task

Immediately after completing the attribution task, the child was given a relative subjective importance (RSI) task. This task was always administered after the attribution task because its purpose was to ascertain whether the three different conditions that had been used in the attribution task had differential effects upon the importance ascribed to the national identity relative to the children's other identities.

A total set of 19 cards was prepared in advance for use in this task. Written on each card were the following words describing all the possible identities which were applicable to all of the children being tested: '5 years old', '6 years old', '7 years old', '8 years old', '9 years old', '10 years old', '11 years old', 'boy', 'girl', 'European', 'English', 'a person from Fleet', 'white', 'black', 'Asian', 'Christian', 'Jewish', 'Hindu' and 'Muslim'. The interviewer knew in advance which of these identities were applicable to any given child. Only those seven cards 
that described each child's actual age, gender, European, national, local, ethnic and religious identities were used with that particular child.

These seven cards were spread out in front of the child in a random arrangement. The experimenter explained that these were all things that could be used to describe the child. The child was then asked: "So all these cards describe you. But if you had to choose just one of these cards because it was the most important for you, which one would you choose?" The chosen card was removed from the set. The child was then asked to choose the next most important card, and so on, until all the cards had been used. The cards were given a score of 1 to 7 , with 1 being the most important and 7 the least important.

The RSI task has been shown to have good concurrent validity, producing scores which correlate highly with scores obtained from both rating scales and paired comparisons (Wilson \& Barrett, 1996). It also produces scores which display patterns of meaningful correlations with parental national attitudes (Wilson \& Barrett, 1996; Wilson, 1998).

The relative subjective importance task

\section{Results}

The first analysis that was conducted examined whether the importance of the English national identity had been enhanced in the two comparative conditions relative to the noncomparative condition. Kruskal Wallis tests revealed that there was no significant difference in the importance attributed to the national identity as a function of condition in the sample as a whole $\left({ }^{2}(2)=0.69, \mathrm{~ns}\right)$, nor in any of the three age groups individually (Young: ${ }^{2}(2)=$ 0.06 , ns; Middle: ${ }^{2}(2)=3.61$, ns; Old: ${ }^{2}(2)=1.00$, ns; N.B.: exactly the same outcome was obtained when the data were analysed using Mann-Whitney $U$ tests to compare the importance attributed to the national identity in the non-comparative condition vs. the two comparative conditions together). Thus, the prediction that the presence of an explicit intergroup comparative context would enhance the importance attributed to membership of the ingroup (English) was not supported. Additional Kruskal Wallis tests revealed that there were also no significant differences across the three conditions in the importance that had been attributed to the age, gender, European, ethnic or religious identities (and only a single difference in the importance ascribed to the local identity by the youngest age group: ${ }^{2}(2)=$ $8.73, p<0.05)$.

Seven further analyses were then conducted in order to assess whether there were differences between the three age groups in the importance attributed to each of the seven identities individually. These analyses revealed significant differences between the three age groups in the importance attributed to all seven identities. Table 2 gives details of the mean importance scores, together with the results of the Kruskal Wallis analyses. The relative importance of the English, European and religious identities increased with age, the relative importance of the age, local and ethnic identities decreased with age, while the relative importance of gender identity first decreased then increased with age (as determined by post hoc ${ }^{2}$ tests, $\left.p<0.05\right)$.

\section{* INSERT TABLE 2 ABOUT HERE *}

The degree of concordance amongst the children within each of the three age groups on the relative importance of the seven identities was assessed using Kendall's coefficient of concordance, which showed that there was highly significant concordance within each age 
group. The rank order of the identities for the youngest age group (running from the most important to the least important) was age, gender, English, local, ethnic, religious, European $(W(6)=218.67, p<0.0001)$; the rank order for the middle age group was English, gender, age, religious, local, European, ethnic $(W(6)=71.96, p<0.0001)$; and the rank order for the oldest age group was English, gender, European, religious, age, local, ethnic $(W(6)=127.58$, $p<0.0001)$. Thus, while the age and gender identities were more important than the national identity in the youngest group of children, national identity was the most important identity in the two older groups of children.

The attribution of positive and negative adjectives to the three national groups

The total numbers of positive and negative adjectives ascribed to the English ingroup in the three different conditions were analysed using a 2 (adjective type: positive vs. negative) x 3 (age group) x 3 (condition) mixed ANOVA, with repeated measures on the first factor and independent groups on the other two factors. This revealed a significant main effect of adjective type $(F(1,295)=730.46, p<0.001)$, with more positive $(M=6.68, S D=1.38)$ than negative $(M=2.37, S D=2.40)$ adjectives being ascribed to the English ingroup overall, and a significant main effect of age $(F(2,295)=19.88, p<0.005)$ with the Young group attributing fewer adjectives overall to the ingroup $(M=8.36, S D=2.33)$ than both the Middle $(M=9.37, S D=2.66)$ and Old $(M=9.52, S D=3.11)$ groups (Scheffe tests, $p<0.05)$.

However, these main effects were qualified by a significant age $\mathrm{x}$ adjective type interaction effect $(F(2,295)=3.43, p<0.05)$ and by a significant age $\mathrm{x}$ condition interaction effect $(F(4,295)=2.56, p<0.05)$. No other effects were significant. The means are shown in Table 3. Post hoc Scheffe tests $(p<0.05)$ were conducted to locate where the age $\mathrm{x}$ adjective type interaction effect fell. These revealed that there was a significant increase in the number of negative adjectives attributed to the English ingroup between the Young $(M=1.89)$ and Old $(M=2.92)$ groups, while there was a significant increase in the number of positive adjectives ascribed to English people between the Young $(M=6.47)$ and Middle groups $(M=$ 7.00). Scheffe tests also revealed that the age $x$ condition interaction effect was due to the fact that the manipulation of comparative context across the three conditions had only had an effect in the Young children, who attributed significantly fewer adjectives overall to English people in the German condition $(M=7.51)$ than in the American $(M=8.83)$ and noncomparative $(M=8.86)$ conditions.

\section{*INSERT TABLES 3 AND 4 ABOUT HERE*}

The total numbers of positive and negative adjectives ascribed to the American and German outgroups in the two comparative conditions were analysed using a 2 (adjective type: positive vs. negative) x 3 (age group) x 2 (outgroup: American vs. German) mixed ANOVA, with repeated measures on the first factor and independent groups on the other two factors. This revealed that there was a significant main effect of adjective type $(F(1,197)=60.65, p$ $<0.001)$, with more positive $(M=4.94, S D=2.31)$ than negative $(M=3.02, S D=2.43)$ adjectives being attributed to the two outgroups overall, and a significant main effect of age $(F(2,197)=15.15, p<0.001)$, with the Young children attributing fewer adjectives $(M=$ $6.82, S D=2.41)$ to the two outgroups than either the Middle $(M=8.41, S D=2.31)$ or the Old $(M=9.14, S D=2.96)$ children (Scheffe tests, $p<0.05)$.

However, these main effects were qualified by an age $\mathrm{x}$ adjective type interaction effect $(F(2,197)=5.61, p<0.005)$ and by an adjective type $\mathrm{x}$ outgroup interaction effect $(F$ $(1,197)=7.14, p<0.01)$. No other effects were significant. The means are shown in Table 4 . 
Post hoc Scheffe tests $(p<0.05)$ were conducted to locate where the interaction effects fell. These revealed that there were significant increases in the total number of positive adjectives attributed to the two outgroups between the Young $(M=3.95)$ and Middle $(M=5.06)$ age groups, and between the Middle and Old $(M=6.17)$ age groups. However, there were no significant differences with age in the number of negative adjectives attributed to the two groups. The adjective type $\mathrm{x}$ outgroup interaction effect was due to the fact that fewer positive adjectives were attributed to the Germans $(M=4.54, S D=2.32)$ than to the Americans $(M=$ $5.44, S D=2.13)$, while more negative adjectives were attributed to the Germans $(M=3.34$, $S D=2.50)$ than to the Americans $(M=2.75, S D=2.32)$.

Using the data from the children in the two comparative conditions, related samples ttests were conducted to compare the number of positive adjectives attributed to the ingroup vs. the outgroup, and the number of negative adjectives attributed to the ingroup vs. the outgroup. These revealed that, overall, the children attributed more positive adjectives to English people than to American people $(t(97)=6.27, p<0.001)$, more positive adjectives to English people than to German people $(t(102)=9.67, p<0.001)$, and more negative adjectives to German people than to English people $(t(102)=4.88, p<0.001)$; this pattern of differences also occurred in all three age groups individually. However, overall, there was no significant difference between the number of negative adjectives attributed to American and English people.

The attributions of 'friendly', 'good', 'aggressive' and 'hardworking' to the English ingroup

It was hypothesised that the children would be less likely to use the adjectives 'friendly' and 'good' for characterising English people when they were being described in relationship to American people. Hierarchical log linear analyses revealed that neither the attribution of 'friendly' nor the attribution of 'unfriendly' to the English ingroup was differentially associated with either condition $\left({ }^{2}(8)=7.92, \mathrm{~ns}\right)$ or age $\mathrm{x}$ condition $\left({ }^{2}(16)=\right.$ $12.28, \mathrm{~ns})$. Similarly, neither the attribution of ' good' nor the attribution of 'bad' to the English ingroup was differentially associated with either condition $\left({ }^{2}(8)=14.57\right.$, ns) or age $\mathrm{x}$ condition $\left({ }^{2}(16)=21.30, \mathrm{~ns}\right)$.

Similarly, it was hypothesised that the children would be less likely to use the adjectives 'aggressive' and 'hardworking' for characterising English people when they were being described in relationship to German people. Again, hierarchical log linear analyses revealed that neither the attribution of 'aggressive' nor the attribution of 'peaceful' to the English ingroup was differentially associated with either condition $\left({ }^{2}(8)=11.44\right.$, ns) or age $x$ condition $\left({ }^{2}(16)=24.93\right.$, ns). Similarly, neither the attribution of 'hardworking' nor the attribution of 'lazy' to the English ingroup was differentially associated with either condition $\left({ }^{2}(8)=3.44, \mathrm{~ns}\right)$ or age $\mathrm{x}$ condition $\left({ }^{2}(16)=15.59, \mathrm{~ns}\right)$.

The contents of the children's stereotypes for the three national groups

The adjectives attributed to the ingroup and to the outgroups were also analysed using correspondence analysis, in order to ascertain whether the total sets of adjectives attributed to the ingroups and the outgroups differed in any other way according to either condition or age. Correspondence analysis (Greenacre, 1984; Hammond, 1988) is a multivariate procedure which uses geometric principles to provide a pictorial representation of the relationships between groups of individuals and the sets of categorical responses which are produced by those individuals. It permits a multidimensional analysis of these categorical responses, and can be used to ascertain which categorical responses are most closely associated with 
different groups of individuals, whether different groups of individuals are associated with significantly different sets of categorical responses, and which particular categorical responses discriminate between the different groups of individuals.

The first correspondence analysis examined whether different adjectives were attributed to the English ingroup by the children in the three conditions (non-comparative vs. American vs. German), irrespective of age. In this correspondence analysis (as in all the subsequent correspondence analyses), each pair of related adjectives was entered as three different response categories: (1) only the negative adjective is attributed to the group in question; (2) both the positive and the negative adjectives in a pair are attributed to the group; (3) only the positive adjective is attributed to the group. The reason for entering the adjective dimensions in this threefold manner was to explore whether there were age- or conditionrelated shifts from positive to negative attributions, and whether there were age- or conditionrelated shifts from univalent (either positive or negative) to multivalent (both positive and negative) attributions on each individual adjective dimension. In order to avoid skewing the outcome of the correspondence analysis by differential rates of occurrence of rarely utilised adjectives (as recommended by Hammond, 1988), only those individual response categories which were used by at least $20 \%$ of the children in any one group were included in the analysis. This criterion was also used in all of the subsequent correspondence analyses.

No significant dimensions emerged in the first correspondence analysis, which examined whether different sets of adjectives were attributed to the English ingroup by the children in the three different conditions (irrespective of age); for the first and largest dimension, which accounted for $72.4 \%$ of the inertia, $\chi^{2}(25)=29.72$, ns. Three further correspondence analyses were then conducted, one on each individual age group in turn, to ascertain whether the manipulation of comparative context had elicited significantly different sets of attributes across the three conditions within any one age group individually. None of these correspondence analyses were significant either. Thus, the sets of adjectives which were attributed to the English ingroup showed no significant differences as a function of condition.

\section{* INSERT FIGURES 1 AND 2 ABOUT HERE *}

Two further correspondence analyses were then conducted, to explore age-related differences in the sets of adjectives which were attributed to the English ingroup (irrespective of condition), and age-related differences in the sets of adjectives which were attributed to the American and German outgroups. The results of these two analyses are shown in Figures 1 and 2. In both analyses, only the first two dimensions were significant (see the footnote to each Figure for details).

The following general guidelines should be used to interpret the plots shown in Figures 1 and 2. The first dimension is represented by the horizontal axis, and the second dimension by the vertical axis. In the plot, the geometric distance of a particular response from a particular group of individuals represents how closely that response is associated with that group of individuals: the smaller the distance, the greater the association. Because both the horizontal and the vertical dimensions are significant in both Figures, the spatial distances in the two dimensions that are defined by the horizontal and the vertical axes may be meaningfully interpreted in both Figures. 
Figure 1 shows that the three age groups attributed significantly different sets of adjectives to the English ingroup. The cluster of univalent positive adjectives which are situated close to the Young group ('good', 'clean', 'hardworking', etc.) shows that the youngest children were more likely to hold a univalent positive stereotype of the English than either of the other two age groups. The Middle group of children were also closely associated with some of the univalent positive adjectives ('happy', 'nice', and 'friendly'), but also with some multivalent attributions ('good + bad' and 'clean + dirty'). The multivalent response categories clustered around the Old group show that the oldest children tended to make more multivalent attributions than either of the other two age groups.

Figure 2 shows that the Young group were more likely than the other two age groups to stereotype the Germans in a univalent negative manner ('bad', 'unfriendly', 'stupid' and 'not nice') and to stereotype the Americans in a univalent positive manner ('good' and 'hardworking'). Some of the Middle group's attributions to Germans were still fairly negative (e.g. 'lazy'), but multivalent attributions to Germans (e.g. 'clever + stupid') were more closely associated with this age group than with the Young group. The Middle group's attributions to Americans and the Old group's attributions to Germans were quite similar, consisting of a mixture of positive univalent and multivalent attributions. Finally, the Old group were more likely than the other two groups to assign multivalent attributes to Americans.

\section{Discussion}

At the end of the Introduction, four specific predictions were outlined. The findings of the present study will be summarised and discussed in relationship to each of these in turn.

Age-related changes in the positivity and negativity of the children's attributions to the three national groups

The first prediction was that, across the 5-11-year-old age range, there would be an increase in the negativity of attributions to the English ingroup, and an increase in the positivity of attributions to the two outgroups. The data showed that such a shift did indeed take place in the children's attributions. Across the age range studied, there was a significant increase in the number of negative characteristics which were attributed to the national ingroup (English people), and a significant increase in the number of positive characteristics which were attributed to the two national outgroups (Americans and Germans). There was no change in the number of negative characteristics attributed to the two outgroups as a function of age. In addition, there was a significant increase in the number of positive characteristics attributed to the national ingroup between approximately 5 and 9 years of age. At all ages, the children attributed more positive adjectives to English people than to either of the two outgroups; they also attributed more negative adjectives to German people than to English and American people at all ages. In other words, the children displayed ingroup favouritism throughout this age range. These findings were obtained using a measure which did not confound the assessment of ingroup and outgroup attitudes, and did not force the children to make attributions of characteristics which were irrelevant to the children's own representations of English, German and American people (cf. Cameron et al., 2001).

The findings of the present study therefore accord with those obtained by Lambert and Klineberg (1967) and Barrett and Short (1992), who also found an increase in positive regard for national outgroups between 5 and 11 years of age. However, the present study provides more detailed information about this developmental trend: this increase in positive regard is 
due to an increase in the attribution of positive (rather than a decrease in the attribution of negative) characteristics to national outgroups. The study also reveals that, across the same age range, the attribution of characteristics to the national ingroup shows a parallel development, namely an increase in the number of negative characteristics which are attributed to it.

The findings of the present study also accord with those reported by Doyle et al. (1988) in relationship to ethnic groups. Doyle and Aboud (1995) have argued that the reduction of ethnic ingroup bias which occurs between 6 and 12 years of age is based upon an emerging understanding that all social groups exhibit a great deal of variability, containing people with both good and bad characteristics. The fact that there was a shift away from univalent to multivalent attributions both to the national ingroup and to national outgroups across the 5-11-year-old age range (Figures 1 and 2) does indeed suggest that a more fundamental shift in children's understanding of large-scale social groups may well be taking place across this age range, with this shift in understanding being applied simultaneously to the child's understanding of both ethnic and national groups.

As noted in the Introduction, Americans and Germans were chosen for use as outgroups in the present study because previous studies have revealed that Americans tend to be the most liked and Germans the most disliked national outgroups for English children. It was reasoned that the use of these two 'affectively extreme' outgroups would provide a robust test of the predictions concerning the attribution of positive and negative characteristics to national outgroups. The fact that similar developmental trends were found for both national outgroups, despite the greater degree of positive regard which the English children had for the American outgroup, suggests that these developmental trends are indeed robust. It should be noted, however, that in the present study, Germans were not described with predominantly negative characteristics (see Table 4), suggesting that this particular sample of children held representations of German people which were in fact positive rather than negative overall.

Thus, the development of children's attitudes to national and ethnic groups appear to follow similar trajectories. It is nevertheless possible that developments in the two domains are not actually related to each other, but occur in parallel, contemporaneously but independently. There are certainly several differentiating features characterising the ethnic and national domains which should caution against an over-ready assimilation of the two domains to one another. For example, in the ethnic domain, there are visible physiognomic markers which distinguish the members of different groups from one another, but there are often no visible markers that distinguish the members of different national groups from one another. Furthermore, the number of national groups which children have to learn about is far greater than the number of groups which children have to learn to distinguish in the ethnic domain. Also, in the ethnic domain, many children have direct personal contact with members of other groups in their everyday environments, whereas relatively few children have direct personal contact in their everyday lives with members of other national groups. It is therefore possible that the developmental task facing the child (to learn about the different groups which exist in each domain) may be much more difficult in the domain of nationality than in the domain of ethnicity. Whether children's development in these two domains is or is not inter-connected is an issue for future studies to determine. 
A further important qualification which needs to be made concerning the present findings is that although they do accord with those obtained in many previous studies (e.g. Barrett \& Short, 1992; Doyle \& Aboud, 1995; Doyle et al., 1988; Lambert \& Klineberg, 1967), there are a few studies in the literature in which very different patterns of development in middle childhood have been reported (e.g. Barrett et al., 1997; Reizábal, Valencia \& Barrett, in press). The most dramatic case is reported by Reizábal et al. (in press), who examined the attributions made by 6-15-year-old children living in the Basque Country to a number of national groups, including Basque, Spanish, French, Italian, British and German people. It was found that, amongst this particular group of children, there were no significant changes with age in the overall positivity-negativity of the attributions which were made to these national groups, or in the numbers of positive and negative adjectives attributed to the groups. In the Basque Country, national identity issues are exceptionally salient due to the severe repression of the Basque language and Basque institutions which occurred under the Franco regime, and amongst adults living in the Basque Country today the sense of national identification is strongly related to their choices concerning the use of the Basque and Spanish languages (Azurmendi, Garcia \& Gonzalez, 1998; Elejabarrieta, 1994; Valencia et al., in press). Interestingly, Reizábal et al. found that, although there were no age-related changes in children's attributions to national groups between 6 and 15 years of age, there were pervasive differences in the children's attributions to national groups as a function of whether they spoke only Basque with their parents in their home, only Spanish in the home, or both Basque and Spanish in the home. Hence, in interpreting the findings of the present study, it is important to bear in mind the fact that what can appear to be robust age-related developmental trends within some socialisation contexts (such as England and North America) might actually be modified very dramatically by the practices of salient socialisation agents operating within other national and/or ethnic contexts (such as the Basque Country).

The finding of the present study that ingroup favouritism was exhibited across the entire 5-11-year-old age range is consistent with the findings of most previous studies (e.g. Barrett et al., in press; Bennett et al., 1998; Lambert \& Klineberg, 1967; Tajfel et al., 1970), including the study by Reizábal et al. (in press), who also found strong evidence for ingroup favouritism at all ages despite the variability in the children's attributions to national groups as a function of their language use. However, this finding does run counter to the findings of Rutland (1999), who only found evidence of national ingroup favouritism from 10 years of age onwards. However, in his study, Rutland used photographs of individual people in order to elicit the children's judgements; it is therefore possible that the children were responding to the particular people who were depicted in these photographs rather than to the social category of the national group as a whole. Rutland also used the term "British" rather than "English" to label the (English) children's national ingroup. However, there is evidence that the term "British" is less salient to English children than the term "English" (Barrett, 1996, 2001, 2002). It is therefore possible that the discrepancy between Rutland's findings and those of other studies are a consequence of the particular methods which he employed.

The stability of the contents of the national ingroup stereotype across comparative conditions

In this study, the children's attributions of characteristics to English people were elicited under three different conditions: either on their own; in conjunction with their attribution of characteristics to American people; or in conjunction with their attribution of characteristics to German people. In line with the research literature on both adults' and children's stereotypes, it had been predicted that these conditions would elicit different attributions from the children. In particular, it was hypothesised that the content of the 
attributions to English people would vary, depending upon the relevance of specific adjectives for capturing the difference between the English ingroup and the particular national outgroup against which the English ingroup was being compared.

However, there was no effect of comparative condition upon the characteristics which were attributed to the English ingroup. This was indicated both by the analyses of the specific adjectives 'friendly', 'unfriendly', 'good', 'bad', 'aggressive', 'peaceful', 'hardworking' and 'lazy' (which were particularly relevant to the comparisons with Americans and Germans), and by the correspondence analyses which took into account all of the adjectives which were available to the children. The absence of any effects of comparative context upon stereotype content was further indicated by the lack of effects involving condition upon the numbers of positive and negative adjectives attributed to the English ingroup (the only condition effect being the finding that the Young children alone attributed significantly fewer adjectives overall to English people in the German condition than in the other two conditions).

It might perhaps be argued that the predicted effects of comparative context failed to occur because the children had insufficient knowledge of the different national groups. Since the cognitive comparison processes which are hypothesised to be responsible for producing changes in stereotype content as a function of comparative context (Haslam et al., 1992, 1995; Hopkins et al., 1997; Oakes et al., 1994) cannot, by definition, operate in a content-free manner, then it might be argued that such effects could not occur in children who are still largely ignorant of the substantive content of national stereotypes. However, while this argument might perhaps be made in relationship to the younger children in the present study, it cannot be made about the older children. Previous studies have shown that national ingroup stereotypes are usually in place by the age of 6 (Lambert \& Klineberg, 1967). Previous studies have also shown that, from the age of 8 years onwards, English children hold detailed stereotypes of both Americans and Germans, and are very willing and able to discuss these stereotypes with adult interviewers (e.g. Barrett et al., 1990; Barrett \& Short, 1992; Wilson et al., 1995). Furthermore, these stereotypes of the ingroup and of Americans and Germans are socially shared by English children. For example, Barrett and Short (1992) found that more than $50 \%$ of the $8-10$-year-old children who they questioned about Germans said that Germans were 'white', 'tall', 'happy', 'aggressive', 'hardworking' and 'spoke German'. This level of detail in children's consensual descriptions of Germans undermines the argument that the older children in this study had not yet acquired any substantive content in their representations of Germans. Alternatively, it might be argued that the manipulation of comparative context failed to have the predicted effects because the comparison outgroups against which the ingroup was compared in the two comparative conditions were not sufficiently salient to the children. However, this argument is also difficult to reconcile with the findings from previous studies (Barrett \& Short, 1992; Wilson et al., 1995) that Americans and Germans are both highly salient national outgroups for English children.

A further possibility might be that the manipulation of comparative context failed to have any effect because of the particular way in which the comparative context was manipulated in this study, which did not serve to promote the salience of the national outgroups sufficiently. This possibility can be examined empirically by enhancing the perceptual and cognitive salience of the comparison outgroup, either by showing the children a video of a scenario in which the distinction between the national ingroup and outgroup is made especially prominent, or by testing children while they are on holiday in an outgroup country. One attempt to enhance the salience of the comparison outgroup was in fact 
attempted by Wilson (1998): in one condition, she showed a video of a soccer match in which the child's own national team (England) was defeated by the national team of the comparison outgroup (Germany); in another condition, the children did not see this video. Within each of these conditions, the children either attributed characteristics to the English ingroup on its own, or in conjunction with the attribution of characteristics to the German outgroup.

However, this method of enhancing the salience of the outgroup also failed to elicit any changes in the contents of the ingroup stereotype as a function of comparative context in the 5-11-year-old children, even in the video condition. Thus, it seems unlikely that the lack of effects of comparative context on ingroup stereotype content in the present study was due merely to the comparison outgroups being insufficiently salient in the experimental setting.

Finally, it might be argued that the manipulation of comparative context failed to have the predicted effects because the particular adjectives which were used in the attribution task were not the most relevant terms for the children to use for describing the three national groups; thus, these adjectives might not have captured the relevant dimensions on which the children themselves differentiated between English, American and German people. However, there are two reasons to doubt this explanation. Firstly, several of the adjectives in the attribution task were used precisely because these are the terms which have been found in previous studies (Barrett et al., 1990; Wilson et al., 1995) to be used spontaneously by English children when talking about German and American people. And secondly, in the attribution task, the children were given explicit instructions to discard any of the adjectives which they felt did not apply to these national groups; there was therefore no reason why the children should have used irrelevant adjectives or adjective dimensions to characterise any of the three national groups. Thus, it is unlikely that the lack of condition effects upon stereotype content was due to the children using inappropriate adjectives in the attribution task for describing the three national groups.

Note that the children were asked to perform different tasks in the non-comparative and comparative conditions. In the non-comparative condition, the child merely had to place in a single box all the adjectives which applied to the English ingroup. However, in the two comparative contexts, the child was confronted with a choice of four boxes, which required much more complex decision-making. The fact that there were no significant differences in the attributions which were made to the ingroup between the comparative and noncomparative conditions, despite these different task demands, suggests that the children's representations of the ingroup were remarkably robust.

Given these various considerations, the present study does indeed seem to imply that children's national stereotypes do not exhibit variability as a function of the prevailing comparative context, unlike adults' national stereotypes (cf. Haslam et al., 1992, 1995; Hopkins et al., 1997). Insofar as the studies on adult national stereotypes have typically utilised college students as participants, it remains an open question as to how, and at what age, contextual variability in national stereotype content does actually emerge. The present study suggests that such variability does not emerge until at least early adolescence.

Perhaps more interestingly from a developmental perspective, though, the present findings also differ from the findings obtained by Sani and Bennett (2001; Sani et al., in press) with children's gender stereotypes which $d o$ exhibit variability depending upon the specific comparison outgroup which is available in the prevailing context. The implication therefore is that 5-11-year-old children exhibit different phenomena in relationship to 
different social identities. It is perhaps not surprising that children's gender identities develop more rapidly than their national identities. Gender identities are known to be highly salient to young children (Lloyd \& Duveen, 1990; Yee \& Brown, 1992, 1994) and have a much greater functional utility in young children's everyday lives than national identities (Bennett et al., 1998). From a theoretical point of view, the fact that different social identities may exhibit different phenomena in children at a given age suggests that identity development is domainspecific (rather than domain-general, as argued by Piaget \& Weil, 1951, Aboud, 1988, and Doyle \& Aboud, 1995). Hence, identity development in middle childhood may be rather more fragmented than some contemporary cognitive-developmental stage-based models (e.g. Aboud, 1988; Aboud \& Amato, 2001) would seem to allow, with the compartmentalisation of self-representations possibly extending even later in development than has previously been suggested (cf. Harter, 1998, 1999).

The issue of stereotype variability clearly requires further investigation. For example, it would be interesting to establish whether children's ethnic stereotypes exhibit contextual variability. This would at least help to elucidate whether ethnic stereotypes follow the same developmental trajectory as national stereotypes (cf. the discussion in the previous section), or whether ethnic stereotypes are more akin to children's gender stereotypes, perhaps due to their greater utility and social salience in the context of children's everyday lives. It would also be of interest to compare the ethnic judgements of children who live within multi-ethnic communities with the judgements of children who live within mono-ethnic communities, in order to establish whether the availability of intergroup comparisons within the child's everyday environment influences the age at which such contextual variability first appears.

Another line of further investigation which would be worth pursuing concerns the extent to which the particular measure that has been used to assess children's stereotypes might affects the particular findings which are obtained in these kinds of studies. It is noteworthy that the present study relied upon categorical responses, with traits being either assigned or not assigned to groups. Sani \& Bennett (2001) similarly used all-or-none categorical attributions to boys and girls. By contrast, Sani et al. (in press) used a 3-point rating scale, whereby the children had to decide whether each individual trait applied to 'most' girls (or boys), 'some' or 'none'. Studies with adults have either employed 7-point scales (running from 'not at all' to 'very much') on which the participants are asked to judge how much each adjective applies to a given group (e.g. Hopkins et al., 1997), or have asked participants to judge the percentage of people in the group to whom each trait applies (e.g. Haslam et al., 1995). These latter procedures clearly allow greater sensitivity in the measurement of judgements. Although there are obvious constraints on the sorts of judgements which young children can be asked to make, it would nevertheless be useful to know whether the use of different measurement methods (e.g. categorical vs. 3-point scales) affects the findings which are obtained.

Age-related changes in the importance ascribed to national identity

The findings which emerged from the RSI task show that the importance which English children ascribe to their national identity increases across the 5-11-year-old age range. The youngest children rated their age and gender identities as being more important to them than their national identity. This outcome does indeed make sense in terms of the greater utility of age and gender in young children's everyday lives. However, it is noteworthy that, amongst both the Middle and Old age groups, national identity was rated by the children as being their most important identity, more important than either age or gender. 
Thus, the prediction that national identity would gradually become more important to the children across the 5-11-year-old age range was supported by the data.

The finding that national identity becomes more important to children across this age range is consistent with the findings of Barrett et al. (1997) and Wilson and Barrett (1996), who also found that national identity typically becomes more important to children during middle childhood. However, the findings of the present study diverge from the findings of these two previous studies in that the children's national identity emerged as the most important identity for the Middle and Old age groups of children. By contrast, Barrett et al. found that even at 12 years of age, across their sample as a whole, the children's gender and age identities were still more important than their national identity. This discrepancy in findings is probably due to the fact that both Barrett et al. and Wilson and Barrett assessed the importance of national identity before telling the children that the study in which they were participating concerned their knowledge and feelings about national groups. Thus, the children's national identity was not cued prior to the assessment of the importance of national identity. In the present study, however, the RSI task was always administered after the attribution task, which would have cued the children that the experiment concerned their beliefs and feelings about national groups (the RSI task was always administered second as its purpose was to ascertain whether the importance of the national identity would be enhanced in the two comparative conditions relative to the non-comparative condition). Thus, the discrepancy in findings was expected. That said, the findings of all three studies are consistent in demonstrating that the sense of national identity becomes more important to children during middle childhood.

Precisely why national identity should become more important to children across this age range is not entirely clear from existing research. One possibility is that, as children's knowledge of national symbols, historical events, geographical territories and national stereotypes develops during this period, the salience and importance of national identity increases as a consequence. This would be consistent with findings from studies which indicate that these kinds of knowledge which are associated with the child's national group membership do indeed develop substantially over the course of middle childhood (Barrett \& Farroni, 1996; Barrett \& Short, 1992; Bourchier, Barrett \& Lyons, 2002; Jahoda, 1962, 1963a, 1963b; Lambert \& Klineberg, 1967; Middleton et al., 1970; Piaget \& Weil, 1951). Another possibility is that, at this time of life, children begin to participate more actively in national traditions, customs, ceremonies and events (cf. Billig, 1995), and it may be that participation in these activities is an important causal factor in fostering a sense of national identity in children. Further research is clearly needed in order to elucidate why national identity increases in importance across this age range.

The stability of the importance ascribed to national identity across comparative conditions

The assessment of the importance of national identity was made immediately after the attribution task in order to ascertain whether the importance of this identity varied across the three experimental conditions. The prediction was that the importance of national identity would be enhanced in the two comparative conditions. Following Oakes et al. (1994), it was hypothesised that, in a situation in which only the ingroup is present, the individual is encouraged to make intra-group comparisons, which would enhance the salience of lowerlevel sub-group categories; in a situation in which both the ingroup and a salient comparison outgroup are present, these sub-group categories would become less salient, and the salience of the ingroup category would increase. 
However, there were no effects of comparative context upon the relative importance which was ascribed to the national identity. Therefore, no evidence emerged from this study to suggest that the cognitive processes postulated by Oakes et al. were occurring in these children as far as their national group membership was concerned. This outcome is in fact consistent with the lack of effects of comparative context upon the children's stereotype content, and serves to reinforce the general conclusion that 5-11-year-old children are relatively insensitive to comparative context when making judgements about national groups.

\section{Conclusions}

This study has revealed various age-related trends in the development of national ingroup bias. Between 5 and 11 years of age, there is a significant increase in the number of negative characteristics which are attributed to the national ingroup, and a significant increase in the number of positive characteristics which are attributed to salient national outgroups. The net result is that, across this age range, there is a reduction in national ingroup bias. However, 5-11- year- old children do still display ingroup favouritism at all ages. In addition, this study has shown that 5-11-year-old children are relatively insensitive to the comparative context in which they make their judgements about national groups. They attribute the same characteristics to their own national group irrespective of whether they are asked to judge this group on its own or in conjunction with a salient national outgroup. The presence of an intergroup comparative context also does not affect the importance which children ascribe to their national identity relative to their other identities. These results have been obtained with English children, who made judgements about their own national ingroup (English people) and about two specific national outgroups (Americans and Germans). It is for future studies to determine the extent to which these findings might apply to children who belong to other national groups, and to the judgements which children make about other national and/or ethnic groups. 


\section{References}

Aboud, F. (1988). Children and prejudice. Oxford: Blackwell.

Aboud, F. \& Amato, M. (2001). Developmental and socialization influences on intergroup bias. In R. Brown \& S.L. Gaertner (Eds.), Blackwell handbook of social psychology: intergroup processes (pp. 65-85). Oxford: Blackwell.

Asher, S.R. \& Allen, V.L. (1969). Racial preference and social comparison processes. Journal of Social Issues, 25, 157-166.

Azurmendi, M.J., Garcia, I. \& Gonzalez, J.L. 1998. Influencia del uso de las lenguas en contacto con la identidad social en la Comunidad Autónoma Vasca. Revista de Psicología Social, 13 (1), 3-10.

Barrett, M. (1996). English children's acquisition of a European identity. In G. Breakwell \& E. Lyons (Eds.), Changing European identities: social psychological analyses of social change (pp. 349-369). Oxford: Butterworth-Heinemann.

Barrett, M. (2001). The development of national identity: a conceptual analysis and some data from Western European studies. In M. Barrett, T. Riazanova, \& M. Volovikova (Eds.), Development of national, ethnolinguistic and religious identities in children and adolescents (pp. 16-58). Moscow: Institute of Psychology, Russian Academy of Sciences.

Barrett, M. (2002). Children's views of Britain and Britishness in 2001. Keynote address presented to the Annual Conference of the Developmental Psychology Section of the British Psychological Society, University of Sussex, $5^{\text {th }}-8^{\text {th }}$ September 2002.

Barrett, M. (in press). Children's knowledge, beliefs and feelings about nations and national groups. Hove, UK: Psychology Press.

Barrett, M., Day, J. \& Morris, E. (1990). English children's conceptions of European people: a pilot study. Paper presented at the Conference on Perception and Cognitive Processes, Trieste, Italy, June 1990.

Barrett, M. \& Farroni, T. (1996). English and Italian children's knowledge of European geography. British Journal of Developmental Psychology, 14, 257-273.

Barrett, M., Lyons, E., Bennett, M., Vila, I., Giménez de la Peña, A., Arcuri, L. \& de Rosa, A.S. (1997). Children's beliefs and feelings about their own and other national groups in Europe. Final Report to the Commission of the European Communities, Directorate-General XII for Science, Research and Development, Human Capital and Mobility (HCM) Programme, Research Network Contract No. CHRX-CT94-0687.

Barrett, M., Lyons, E. \& del Valle, A. (in press). The development of national identity and social identity processes: do social identity theory and self-categorization theory provide useful heuristic frameworks for developmental research? In M. Bennett \& F. Sani (Eds.), The development of the social self. Hove, UK: Psychology Press.

Barrett, M. \& Short, J. (1992). Images of European people in a group of 5-10 year old English schoolchildren. British Journal of Developmental Psychology, 10, 339-363.

Bennett, M., Barrett, M., Karakozov, R., Kipiani, G., Lyons, E., Pavlenko, V., \& Riazanova, T. (in press) Young children's evaluations of the ingroup and of outgroups: A multinational study. Social Development.

Bennett, M., Lyons, E., Sani, F. \& Barrett, M. (1998). Children's subjective identification with the group and in-group favoritism. Developmental Psychology, 34, 902-909.

Bigler, R. \& Liben, L. (1993). A cognitive-developmental approach to racial stereotyping and reconstructive memory in Euro-American children. Child Development, 64, 15071519.

Billig, M. (1995). Banal nationalism. London: Sage Publications.

Bourchier, A., Barrett, M. \& Lyons, E. (2002). The predictors of children's geographical 
knowledge of other countries. Journal of Environmental Psychology, 22, 79-94. Cameron, J.A., Alvarez, J.M., Ruble, D.N. \& Fuligni, A.J. (2001). Children's lay theories about ingroups and outgroups: reconceptualizing research on prejudice. Personality and Social Psychology Review, 5, 118-128.

Clark, K.B. \& Clark, M.P. (1958). Racial identification and preference in Negro children. In E.E. Maccoby, T.M. Newcomb \& E.L. Hartley (Eds.), Readings in Social Psychology ( $3^{\text {rd }}$ edition, pp. 602-611). New York: Holt, Rinehart and Winston. (Originally published 1947.)

Davey, A. (1983). Learning to be prejudiced. London: Edward Arnold.

Diab, L.N. (1963a). Factors affecting studies of national stereotypes. Journal of Social Psychology, 59, 29-40.

Diab, L.N. (1963b). Factors determining group stereotypes. Journal of Social Psychology, 61, 3-10.

Doyle, A.B. \& Aboud, F. (1995). A longitudinal study of white children's racial prejudice as a social-cognitive development. Merrill-Palmer Quarterly, 41, 209-228.

Doyle, A.B., Beaudet, J. \& Aboud, F. (1988). Developmental patterns in the flexibility of children's ethnic attitudes. Journal of Cross-Cultural Psychology, 19, 3-18.

Elejabarrieta, F. 1994. Social positioning: a way to link social identity and social representations. Social Science Information, 33, 241-253.

Greenacre, M.J. (1984). Theory and application of correspondence analysis. London: Academic Press.

Hammond, S. (1988). Corres 1.0: a programme for correspondence analysis of contingency tables on IBM compatible micros. Department of Psychology, University of Surrey.

Harter, S. (1998). The development of self-representations. In W. Damon \& N. Eisenberg (Eds.), Handbook of Child Psychology, Volume 3: Social, Emotional and Personality Development (pp. 553-617). New York: Wiley.

Harter, S. (1999). The Construction of the Self: A Developmental Perspective. New York: Guilford Press.

Haslam, S.A., Oakes, P.J., Turner J.C. \& McGarty, C. (1995). Social categorization and group homogeneity: changes in the perceived applicability of stereotype content as a function of comparative context and trait favourableness. British Journal of Social Psychology, 34, 139-160.

Haslam, S.A., Turner, J.C., Oakes, P.J., McGarty, C. \& Hayes, B.K. (1992). Contextdependent variation in social stereotyping 1: the effects of intergroup relations as mediated by social change and frame of reference. European Journal of Social Psychology, 22, 251-278.

Hopkins, N. \& Murdoch, N. (1999). The role of the 'other' in national identity: exploring the context-dependence of the national ingroup stereotype. Journal of Community and Applied Social Psychology, 9, 321-338.

Hopkins, N., Regan, M. \& Abell, J. (1997). On the context-dependence of national stereotypes: some Scottish data. British Journal of Social Psychology, 36, 553-563.

Jahoda, G. (1962). Development of Scottish children's ideas and attitudes about other countries. Journal of Social Psychology, 58, 91-108.

Jahoda, G. (1963a). The development of children's ideas about country and nationality, Part I: The conceptual framework. British Journal of Educational Psychology, 33, 47-60.

Jahoda, G. (1963b). The development of children's ideas about country and nationality, Part II: National symbols and themes. British Journal of Educational Psychology, 33, 143-153.

Jaspers, J.M.F., van de Geer, J.P., Tajfel, H. \& Johnson, N. (1972). On the development of 
national attitudes in children. European Journal of Social Psychology, 2, 347-369.

Johnson, N. (1966). What do children learn from war comics? New Society, 8, 7-12.

Johnson, N. (1973). Development of English children's concept of Germany. Journal of Social Psychology, 90, 259-267.

Johnson, N., Middleton, M. \& Tajfel, H. (1970). The relationship between children's preferences for and knowledge about other nations. British Journal of Social and Clinical Psychology, 9, 232-240.

Katz, P. \& Zalk, S. (1978). Modification of children's racial attitudes. Developmental Psychology, 14, 447-461.

Lambert, W.E. \& Klineberg, O. (1967). Children's views of foreign peoples: a cross-national study. New York: Appleton-Century-Crofts.

Lloyd B. \& Duveen, G. (1990). A semiotic analysis of the development of social representations of gender. In G. Duveen \& B. Lloyd (Eds.), Social representations and the development of knowledge (pp. 27-46). Cambridge: Cambridge University Press.

Middleton, M., Tajfel, H. \& Johnson, N. (1970). Cognitive and affective aspects of children's national attitudes. British Journal of Social and Clinical Psychology, 9, 122-134.

Oakes P.J., Haslam, S.A. \& Turner, J.C. (1994). Stereotyping and social reality. Oxford: Blackwell.

Piaget, J. \& Weil, A. (1951). The development in children of the idea of the homeland and of relations with other countries. International Social Science Bulletin, 3, 561-578.

Reizábal, L., Valencia, J. \& Barrett, M. (in press). National identifications and attitudes to national ingroups and outgroups amongst children living in the Basque Country. Infant and Child Development.

Rutland, A. (1999). The development of national prejudice, in-group favouritism and selfstereotypes in British children. British Journal of Social Psychology, 38, 55-70.

Sani, F. \& Bennett, M. (2001). Contextual variability in young children's gender ingroup stereotype. Social Development, 10, 221-229.

Sani, F., Bennett, M., Mullally, S. \& MacPherson, J. (in press). On the assumption of fixity in children's stereotypes: a reappraisal. British Journal of Developmental Psychology.

Spears, R. \& Manstead, A.S.R. (1989). The social context of stereotyping and differentiation. European Journal of Social Psychology, 19, 101-121.

Tajfel, H., Jahoda, G., Nemeth, C., Campbell, J. \& Johnson, N. (1970). The development of children's preference for their own country: a cross-national study. International Journal of Psychology, 5, 245-253.

Valencia, J., Elejabarrieta, F., Perera, S., Reizabal, L., Barrett, M., Vila, I., Gil de Montes, L., Ortiz, G. \& M. Larrañaga (in press). Conflictual national identities and linguistic strategies as positioning tools in children and adolescents. In Proceedings of the 5th International Conference on Social Representations, "New Constructions", Montreal, Canada, 2000.

Vaughan, G.M. (1964). The development of ethnic attitudes in New Zealand school children. Genetic Psychology Monographs, 70, 135-175.

Williams, J.E., Best, D.L., Boswell, D.A., Mattson, L.A. \& Graves, D.J. (1975). Preschool racial attitude measure II. Educational and Psychological Measurement, 35, 3-18.

Williams, J.E. \& Morland, J.K. (1976). Race, color, and the young child. Chapel Hill: University of North Carolina Press.

Wilson, H. (1998). The development of national identity in 5 to 11 year old English schoolchildren. Unpublished PhD thesis, University of Surrey. 
Wilson, H., Barrett, M. \& Lyons, E. (1995). English children's beliefs and feelings about national groups in Europe: a pilot study. Paper presented at the Second European Workshop on Children's Beliefs and Feelings about their Own and Other National Groups in Europe, University of Girona, Spain, July 1995.

Wilson, H. \& Barrett, M. (1996). The development of national identity in children: a study to investigate the relationship between child and parental attitudes. Poster presented at the British Psychological Society Developmental Section Annual Conference, Oxford, September 1996.

Yee, M.D. \& Brown, R.J. (1992). Self-evaluations and intergroup attitudes in children aged three to nine. Child Development, 63, 619-629.

Yee, M.D. \& Brown, R.J. (1994). The development of gender differentiation on young children. British Journal of Social Psychology, 33, 183-196. 
Table 1: The mean age, age range, and number of subjects within each condition; mean ages are given in years.

\begin{tabular}{|c|c|c|c|c|}
\hline & Young & Middle & Old & Total \\
\hline non- & 6.69 & 8.63 & 10.52 & 8.52 \\
comparative & $5.91-7.75$ & $7.83-9.58$ & $9.83-11.75$ & $5.91-11.75$ \\
& $\mathrm{~N}=38$ & $\mathrm{~N}=31$ & $\mathrm{~N}=33$ & $\mathrm{~N}=102$ \\
\hline American & 6.89 & 9.06 & 10.51 & 8.73 \\
comparative & $5.75-7.84$ & $7.75-9.75$ & $9.83-11.67$ & $5.75-11.67$ \\
& $\mathrm{~N}=37$ & $\mathrm{~N}=33$ & $\mathrm{~N}=32$ & $\mathrm{~N}=102$ \\
\hline German & 6.93 & 8.94 & 10.61 & 8.64 \\
comparative & $5.60-7.75$ & $7.85-9.70$ & $10.00-11.75$ & $5.60-11.75$ \\
& $\mathrm{~N}=41$ & $\mathrm{~N}=31$ & $\mathrm{~N}=31$ & $\mathrm{~N}=103$ \\
\hline Total & 6.84 & 8.88 & 10.55 & 8.63 \\
& $5.60-7.84$ & $7.75-9.75$ & $9.83-11.75$ & $5.60-11.75$ \\
& $\mathrm{~N}=116$ & $\mathrm{~N}=95$ & $\mathrm{~N}=96$ & $\mathrm{~N}=307$ \\
\hline
\end{tabular}


Table 2: The mean importance scores for each of the seven identities (with standard deviations in parentheses), broken down according to the children's age, together with the results of the Kruskal Wallis analyses; the lower the score, the more important the identity.

IDENTITY/

Age Group

\section{ENGLISH}

Young

Middle

Old

\section{EUROPEAN}

Young

Middle

Old

\section{RELIGIOUS}

Young

Middle

Old

AGE

Young

Middle

Old

LOCAL

Young

Middle

Old

\section{ETHNIC}

Young

Middle

Old

\section{GENDER}

Young

Middle

Old
Mean

Importance

$3.60(1.62)$

$2.81(1.58)$

$2.69(1.28)$

$5.49(1.56)$

$4.26(1.81)$

$3.52(1.67)$

$5.06(1.97)$

$3.87(2.63)$

$3.96(2.46)$

$2.23(1.43)$

$3.84(1.70)$

$4.22(1.92)$

$3.63(1.78)$

$4.08(1.83)$

4.67 (1.53)

$5.03(1.47)$

$5.38(1.61)$

$5.76(1.56)$

$3.73(1.75)$

$3.18(1.75)$

\section{Kruskal}

Wallis

$\chi^{2}(2)=20.08$

$p<0.001$

$\chi^{2}(2)=61.65$

$p<0.0001$

$\chi^{2}(2)=10.455$

$p<0.01$

$\chi^{2}(2)=68.79$

$p<0.0001$

$\chi^{2}(2)=17.35$

$p<0.001$

$\chi^{2}(2)=16.58$

$p<0.001$

$\chi^{2}(2)=12.87$

$p<0.01$ 
Table 3: The mean numbers of positive and negative adjectives attributed to the English ingroup (with standard deviations in parentheses), broken down by age and condition.

\begin{tabular}{|c|c|c|c|c|}
\hline AGE GROUP & CONDITION & POSITIVE & NEGATIVE & TOTAL \\
\hline \multirow[t]{4}{*}{ Young } & non-comparative & $\begin{array}{l}6.62 \\
(1.82)\end{array}$ & $\begin{array}{l}2.24 \\
(2.73)\end{array}$ & $\begin{array}{l}8.86 \\
(2.67)\end{array}$ \\
\hline & $\begin{array}{l}\text { American } \\
\text { comparative }\end{array}$ & $\begin{array}{l}6.66 \\
(1.14)\end{array}$ & $\begin{array}{l}2.17 \\
(2.06)\end{array}$ & $\begin{array}{l}8.83 \\
(2.22)\end{array}$ \\
\hline & $\begin{array}{l}\text { German } \\
\text { comparative }\end{array}$ & $\begin{array}{l}6.17 \\
(0.97)\end{array}$ & $\begin{array}{l}1.34 \\
(1.71)\end{array}$ & $\begin{array}{l}7.51 \\
(1.85)\end{array}$ \\
\hline & mean & $\begin{array}{l}6.47 \\
(1.36)\end{array}$ & $\begin{array}{l}1.89 \\
(2.22)\end{array}$ & $\begin{array}{l}8.36 \\
(2.33)\end{array}$ \\
\hline \multirow[t]{4}{*}{ Middle } & non-comparative & $\begin{array}{l}7.00 \\
(1.51)\end{array}$ & $\begin{array}{l}2.42 \\
(2.81)\end{array}$ & $\begin{array}{l}9.42 \\
(3.20)\end{array}$ \\
\hline & $\begin{array}{l}\text { American } \\
\text { comparative }\end{array}$ & $\begin{array}{l}6.82 \\
(1.18)\end{array}$ & $\begin{array}{l}2.45 \\
(2.00)\end{array}$ & $\begin{array}{l}9.27 \\
(2.35)\end{array}$ \\
\hline & $\begin{array}{l}\text { German } \\
\text { comparative }\end{array}$ & $\begin{array}{l}7.19 \\
(1.01)\end{array}$ & $\begin{array}{l}2.23 \\
(2.42)\end{array}$ & $\begin{array}{l}9.42 \\
(2.46)\end{array}$ \\
\hline & mean & $\begin{array}{l}7.00 \\
(1.24)\end{array}$ & $\begin{array}{l}2.37 \\
(2.40)\end{array}$ & $\begin{array}{l}9.37 \\
(2.66)\end{array}$ \\
\hline \multirow[t]{4}{*}{ Old } & non-comparative & $\begin{array}{l}5.76 \\
(1.90)\end{array}$ & $\begin{array}{l}3.12 \\
(2.41)\end{array}$ & $\begin{array}{l}8.88 \\
(3.57)\end{array}$ \\
\hline & $\begin{array}{l}\text { American } \\
\text { comparative }\end{array}$ & $\begin{array}{l}6.78 \\
(1.01)\end{array}$ & $\begin{array}{l}2.72 \\
(2.50)\end{array}$ & $\begin{array}{l}9.50 \\
(2.65)\end{array}$ \\
\hline & $\begin{array}{l}\text { German } \\
\text { comparative }\end{array}$ & $\begin{array}{l}7.32 \\
(0.87)\end{array}$ & $\begin{array}{l}2.90 \\
(2.69)\end{array}$ & $\begin{array}{l}10.23 \\
(2.95)\end{array}$ \\
\hline & mean & $\begin{array}{l}6.60 \\
(1.49)\end{array}$ & $\begin{array}{l}2.92 \\
(2.51)\end{array}$ & $\begin{array}{l}9.52 \\
(3.11)\end{array}$ \\
\hline
\end{tabular}


Table 4: The mean numbers of positive and negative adjectives attributed to the American and German outgroups by the children in the two comparative conditions (with standard deviations in parentheses), broken down by age and condition.

AGE GROUP

Young

Middle

Old

American
German

mean

OUTGROUP

American

German

mean

American

German

mean

(1.96)

6.17

(1.75)

(1.98)

3.46

(2.17)

3.95

(2.31)

\subsection{6}

4.55

(2.13)

\subsection{6}

6.38

(1.52)
2.28

(2.31)

6.78

3.39

(2.49)

6.85

(2.12)

2.87

6.82

(2.35)

(2.41)

3.31

(2.31)

8.87

(2.52)

3.39

7.94

(2.43)

(2.00)

3.35

(2.35)

8.41

(2.31)

2.72

9.09

(2.54)

(3.06)

$5.97 \quad 3.22$

(2.65)

9.19

(2.89)

2.97

9.14

(2.59)

(2.96) 
Figure 1: Adjective attribution to the English ingroup by the three age groups

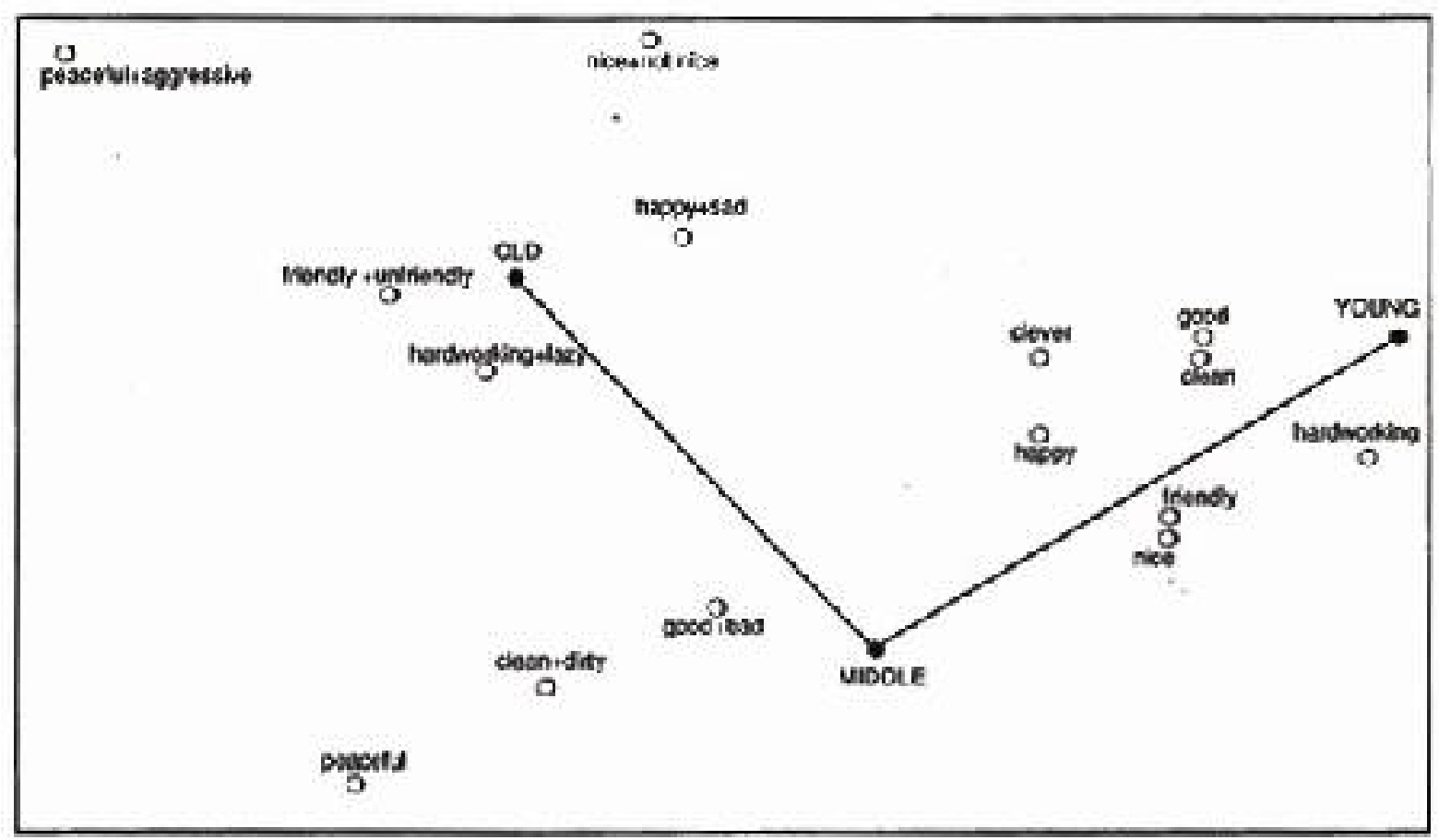

Dimension 1: $\chi^{2}(16)=54.63, \mathrm{p}<0.0001, \%$ of inertia $=68.52$

Dimension $2: \chi^{2}(14)=24.91, \mathrm{p}<0.05, \%$ of inertia $=31.48$ 
Figure 2: Adjective attribution to the American and German outgroups by the three age groups

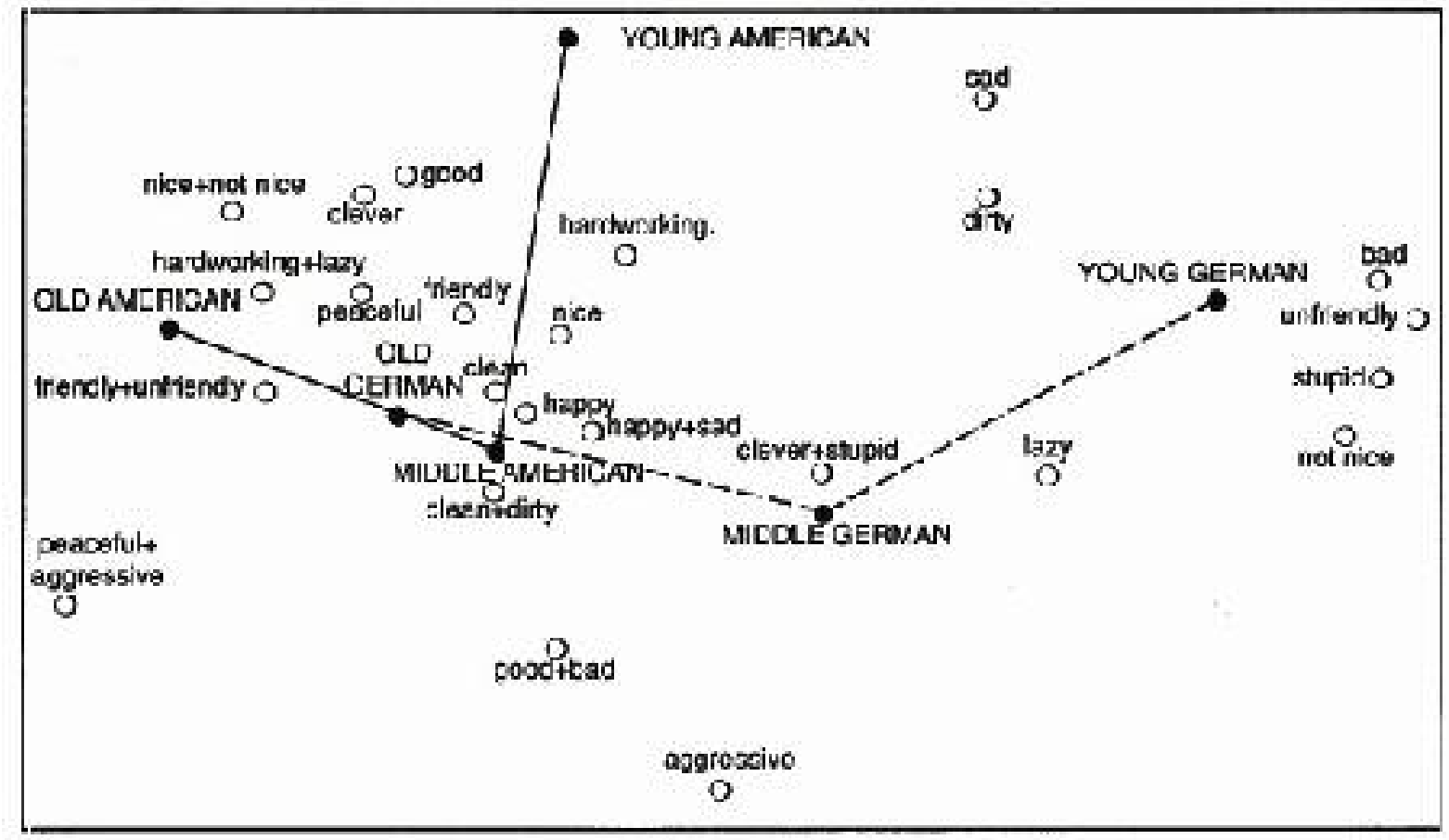

Dimension 1: $\chi^{2}(28)=360.83, \mathrm{p}<0.0001, \%$ of inertia $=57.49$

Dimension 2: $\chi^{2}(26)=113.53, \mathrm{p}<0.0001, \%$ of inertia $=18.67$ 